Née à Québec, Christiane Frenette détient une maîtrise en littérature québécoise de l'Université Laval. Elle enseigne la litterature au Collège Lévis-Lauzon. Elle a collaboré à quelques revues et elle a participé à plusieurs récitals de poésie. En 1986 elle a reçu le prix Octave-Crémazie pour son recueil Indigo nuit (Leméac, 1986). Son second recueil Cérémonie mémoire, paru aux Ecrits des Forges en 1989, a été finaliste au Prix du Gouverneur Général du Canada pour 1989.

\title{
Sous le regard des foules hurleuses
}

\author{
1. \\ des océans meurent sous nos yeux \\ nous caressons le sable et la batture \\ sans avouer ce que nous devons au destin \\ derrière le paysage s'élève en fumée \\ mais nous préférons l'opaque à la vérité \\ quelques oiseaux osent tourner \\ autour de nos certitudes \\ nous buvons à une table désertée \\ un vin mauvais \\ là-bas au fond l'arbre gémit \\ et nous reproche \\ la petitesse du monde
}




\section{2.}

chaque nuit des femmes se jettent des ponts sous le regard des foules hurleuses

et les marees ajoutent leur voix à la douleur au fond des cales les rats perpétuent l'odyssée nous redécouvrons le nouveau monde chaque matin dans une tasse de café les siècles se superposent l'air charrie les parfums la lumière se faufile les arbres tremblent nous saccageons tout nous refaisons l'histoire déplaçons les cours d'eau nous n'avons plus que des rêves d'échiquier nous attendons le signal des chronometres pour tout voir à la fois la mer le ciel et ce ruban de terre où nous cherchions le bonheur

3.

devant les façades nous nous écroulons parfois terrassés par la révélation de notre solitude seulement un regard une ombre qui frôle nos cheveux et voilà toute la forêt à nouveau embrasée nous ne vivons que pour les désastres les lèvres plus rouges le coeur plus pâle nous ne reconnaissons plus la cruelle dérision des arènes ni la splendeur désespérée des bêtes la place est mise à feu et à sang nous ne sommes vivants que parmi les débris 